\title{
Minimal refinements of specifications in modal and temporal logics
}

Nikos Gorogiannis ${ }^{1}$ and Mark Ryan ${ }^{2}$

${ }^{1}$ School of Computing, University of the West of England, BS 16 1QY, Bristol, UK. E-mail: Nikos.Gorogiannis@googlemail.com

${ }^{2}$ School of Computer Science, University of Birmingham, B15 2TT, Birmingham, UK. E-mail: M.D.Ryan@bham.ac.uk

\section{Erratum to: Form Asp Comp (2007) 19:35-62} DOI 10.1007/s00165-006-0014-3

Due to a typesetting error, the title was incorrect and should read as above. 